\title{
ECONOMIC ANALYSES, INJURY LEVELS AND THRESHOLDS FOR EFFECTIVE MANAGEMENT OF EARIAS VITTELLA (FAB.) ON GOSSYPIUM HIRSUTUM
}

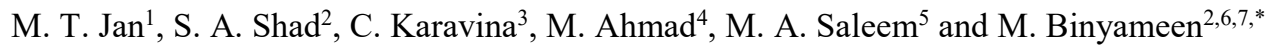 \\ ${ }^{1}$ Entomology Section, Central Cotton Research Institute, Multan, Pakistan; ${ }^{2}$ Department of Entomology, Faculty of \\ Agricultural Sciences and Technology, Bahauddin Zakariya University, Multan, Pakistan \\ ${ }^{3}$ Department of Crop Science, Faculty of Agriculture and Environmental Science, Bindura University of Science \\ Education, Bindura, Zimbabwe; ${ }^{4}$ Department of Entomology, Pir Mehr Ali Shah, Arid Agriculture University \\ Rawalpindi, Pakistan; ${ }^{5}$ Faculty of Life Sciences, University of Central Punjab, Lahore, Pakistan; ${ }^{6}$ Faculty of Forestry and \\ Wood Sciences, EXTEMIT-K, Czech University of Life Sciences, Kamýcká 1176, Prague 6, Suchdol 165 21, Czech \\ Republic ; ${ }^{7}$ Chemical Ecology Laboratory, Department of Entomology, Pennsylvania State University, University Park, \\ 16802 PA, USA. \\ *Corresponding author's email: mbinyameen@bzu.edu.pk
}

\begin{abstract}
Spotted bollworm, Earias vittella Fab. (Lepidoptera: Noctuidae), is a serious insect pest of cotton that reduces crop yield and deteriorates lint quality. Field experiments were conducted at the Central Cotton Research Institute, Multan, Pakistan for two consecutive years (2009 and 2010) to estimate economic injury level (EIL) and economic threshold level (ETL). For economic analyses, gain threshold (GT) and benefit-cost ratio (BCR) were assessed by spraying cypermethrin, deltamethrin and spinosad at four thresholds levels $(0,3,5$ and $7 \%$ damage) and compared with unsprayed treatment (control) for a long and a short duration cotton genotype. The numbers of damaged fruits were almost similar while larval populations and the numbers of healthy fruits were different between the two genotypes. Insecticides applications at selected percent damage levels kept E. vittella larval infestation and bolls damage well below from the total fruit losses of $60-74 \%$ in unsprayed treatment. Increase in percent damage levels decreased the cost of protection (CP) and the net monetary profit (NMP). ETL for long duration genotype (CIM-496) is suggested at 5\% damage level with a larval population of 1.12-1.22 larvae per 25 plants (GT basis) and 4.5 larvae per 25 plants (BCR basis). For short duration genotype (CIM-506), ETL at 3\% damage level with larval population of 1.4-1.33 larvae per 25 plants and 3.3 to 3.9 larvae per 25 plants on GT and BCR basis, respectively is recommended. Timely application of insecticides at ETLs is suggested as economical mean for an effective control of E. vittella on cotton crop.
\end{abstract}

Keywords: Cotton, ETL, larval population, pest management, gain threshold, benefit-cost ratio https://doi.org/10.36899/JAPS.2020.3.0082 Published online March 25, 2020

\section{INTRODUCTION}

Cotton is an important economic crop but attacked by many insect pests which results in economic losses worldwide. Cotton bollworms complex in Asian region mainly comprises of two Earias species (E. vittella and E. insulana), Helicoverpa armigera and Pectinophora gossypiella causing up to $60 \%$ yield loss in cotton production (Vennila et al., 2005). Spotted bollworm, E. vittella, is one of the most injurious insect pest species (Somashekara et al., 2011) whose larvae feed on buds, flowers and bolls leading to premature drop of 20 to $26 \%$ flowering bodies (Dhawan et al. 1990). One larva can potentially damage several fruits before it reaches to pupal stage. Infested bolls produce poor quality lint which results in both low economic yield and prices in market (Maurice, 2010). High fruit damage potential and internal feeding habits of $E$. vittella makes it a very difficult insect pest to manage.
Proper and regular (fixed interval) pest scouting of cotton crop requires certain crop damage or insect pest population levels to be considered at under and/or near to economic losses using economic injury level (EIL) and economic threshold level (ETL). Economic threshold helps the rationalize use of pesticides and serve as one of the key factors for profitable pest management. Such developments of economic thresholds require knowledge of pest biology and behavior, insect pest damage and crop response to damage (Nibouche et al., 2007) and damage cost (Stone and Pedigo, 1972). Cost-benefit ratio is feasible where threshold is based on low cost of control with effective pest management population decline (Anonymous, 2015). These concepts have successfully and widely been adopted to generate management guidelines for insect pests in many cropping systems (Riley, 2008), unfortunately scarce in case of E. vittella management in cotton crop.

Certain population of insect pests at an established economic threshold provides economic 
benefits of less cost for management with higher crop yield. For example, Cydia ptychora (Meyrick) at a population of 0.45 larvae per soybean plant (Abhilash and Patil, 2010) and $H$. armigera (Hübner) population below 0.79 larvae per plant achieved excellent control in pigeon pea (Reddy et al., 2001). Based on unit crop area, estimated EIL and ETL for H. armigera on chickpea for two years at 1.2 and 0.95 , and 0.9 and 0.73 larva per meter row, respectively, were found effective (Zahid et al., 2008). Likewise, EIL and fixed ETL for Anarsia lineatella at112 and 84 larvae per sampling unit, respectively, on Prunus persica also served the purpose of effective population management well below economic loss stage (Damos and Savopoulou-Soultani, 2010).

In any cropping system, genotypes with different crop maturity durations play vital role in development of crop management strategies (Raper and Gwathmey, 2014). For instance, cultivation of short season cotton varieties than conventional long season varieties offer several potential benefits to growers (Silvertooth and Farr, 2001). Benefits of earliness in cotton was assumed to reduce late season pest infestations, less insect generations and diseases, and increased economic returns by reducing input costs and crop damages (Anderson et al., 1976). Crop duration as an important determinant of ETL and EIL requires determining them on different growth period cotton genotypes.

Farmers extensively use chemical insecticides for $E$. vittella control in cotton without considering its ETL and EIL. It has also been observed in Pakistan that farmers deal all types of genotypes without considering the crop life duration in the field conditions. One of the major reasons of this is lack of record of ETL or EIL based studies on E. vittella on cotton crop. Therefore, there is a dire need to determine ETL and EIL of this pest. The present study was conducted to determine the EIL and ETL of E. vittella on cotton genotypes having different duration (total crop life) that will be helpful for effective control of this insect pest.

\section{MATERIALS AND METHODS}

Research site and experimental design: Field experiments were conducted at the Central Cotton Research Institute, Multan ( $\left.30^{\circ} 15^{\prime} \mathrm{N}, 7^{0} 36^{\prime} \mathrm{E}\right)$, Pakistan for two consecutive years; during 2009 and 2010 cropping seasons. Two commercial cotton varieties, CIM-496 (long duration) and CIM-506 (short duration) were sown in May by following split plot design with following treatments (damage thresholds):1\% damage $\left(\mathrm{T}_{1}\right), 3 \%$ damage $\left(\mathrm{T}_{2}\right), 5 \%$ damage $\left(\mathrm{T}_{3}\right), 7 \%$ damage $\left(\mathrm{T}_{4}\right)$ of E. vittella and unsprayed treatment $\left(\mathrm{T}_{5}\right)$. Each set of experiment was replicated three times with cotton varieties as main plot factors while treatments were placed in subplots. Plot size, and row to row and plant to plant spacing were $84.18 \mathrm{~m}^{2}, 76 \mathrm{~cm}$ and $22.9 \mathrm{~cm}$, respectively. Recommended agronomic practices were adopted till crop termination.

\section{Classification of the genotypes on crop duration bases}

Arshad et al. (2007) and Afzal and Khan (2015) classified CIM-496 as long-duration genotype and CIM506 as short season genotype on the bases of crop duration. The former genotype completes its cycle in 140-160 days (till November) whereas the latter one takes 100-120 days (up to mid-October).

Pest assessment: Pest assessment observations were initiated from first week of July till mid-October in 2009 and end October 2010. For each subplot, a row was selected randomly to observe five plants randomly selected to record number of total damaged fruits (including immature and mature) and larval population of E. vittella. The crop was sown during $3^{\text {rd }}$ week of May in both years. For CIM-496 $1^{\text {st }}$ spray was initiated during $3^{\text {rd }}$ week of July at $1 \%$ TL, whereas CIM-506 $1^{\text {st }}$ spray was initiated during $1^{\text {st }}$ week of August. Data for maintaining tested percent damage levels were recorded after 3 days of insecticides spray to ensure different percent damage levels. For this purpose, three insecticides viz., cypermethrin, deltamethrin and spinosad were used for first three consecutive applications as single insecticide, respectively. Data for larval population and percent damage from treatments were recorded at weekly interval till crop harvest. Crops were harvested at October end in 2009 and third week of November in 2010 to check the response of long duration (CIM-496) and short duration (CIM-506) genotypes based on open bolls percentages

Statistical analysis: All statistical tests were carried out using statistical software, Statistix 8.1 (McGraw-Hill, 2008) ((Anonymous, 2014).). Three- way ANOVA was used to compare genotypes, treatments and the interaction between genotype and treatments for total damaged fruits, total larval population and total fruiting parts.

Number of total damaged fruit, larval population and yield (tone ha ${ }^{-1}$ ) for each genotype was analyzed with two-way ANOVA. The means were separated using the Duncan Multiple Rang (DMR) Test at $p \leq 0.05$, where significant differences existed and presented in Table 2 \& 3. The economic analysis including NMP (US $\$$ ha ${ }^{-1}$ ) and CP (US\$ ha ${ }^{-1}$ ) is presented in Table 4 and EIL and ETL in Table 5.

\section{Estimation of EIL \& ETL}

Gain threshold (GT): EIL was calculated using the method of Stone and Pedigo (1972) and Ogunlana and Pedigo (1974) as follow.
$\mathbf{E I L}=\mathbf{G T} / \mathbf{b}$ 
Where $b=$ regression coefficient derived from the linear regression equation and the results are shown in Table 4: Determination of EIL requires an estimate of the gainthreshold (GT), defined in terms of tons ha ${ }^{-1}$. GT, which estimates the yield increase in seed cotton, needed to compensate for control cost, was calculated for each treatment using the equation:

\section{GT $=$ CP / MV (ii)}

Where $\mathrm{CP}=$ cost of protection (US\$/ha) and MV $=$ market value of seed cotton yield /ha (US\$/tons). The cost of insecticides, labor cost and rate of seed cotton is given in Table-1. For EIL, CP is usually considered for zero level of pest in the field.

Whereas, $b$ is calculated from following equation

$\mathbf{Y}=\mathbf{a}-\mathbf{b x}$ (iii):

Where $\mathrm{Y}=$ potential yield, $\mathrm{a}=$ expected yield loss, at zero level of infestation, $b=$ regression coefficient or yield loss in tons ha $^{-1}$ caused by one larva per 5 plant, and $\mathrm{x}=$ number of $E$. vittella larvae per five plants and shown in Fig 1. The negative sign of $b$ in the equation iii, indicates the yield per hectare decreased with the unit number of larval population increased.

Benefit - cost ratio (BCR) estimation: One commonly used rule of thumb in IPM programs is adoption of Benefit: Cost Ratio (BCR) of 2:1. This means that action is only taken when the value of likely damage prevented is twice the cost of control. This rule is the most feasible where the threshold is based on a very low cost of control option. By definition of EIL, when "BCR=1" (Stone and Pedigo 1972), EIL was calculated from the regression equation "Y $=\mathbf{a x}+\mathbf{b}$ " between BCR (dependent variable) and larval population (independent variables) and the results are given in Table 6 and Fig 2.

$\mathrm{ETL}=75 \%$ of EILs

In this study, ETL was fixed at $75 \%$ of the EILs following the findings of Higley and Pedigo (1993), Kovanci et al. (2005), Zahid et al. (2008)and Damos and Savopoulou-Soultani (2010).

Table-1. Cost of insecticides used, daily wages cost and seed cotton yield for years 2009 and 2010.

\begin{tabular}{l|lcc}
\hline Items & \multicolumn{1}{|c}{ Details } & Dose $\left(\boldsymbol{m l ~ h a}^{-1}\right)$ & Cost (US\$) \\
\hline Insecticide & Spinosad 480 EC (Dow Agro Sciences, Pakistan) & 193 & 40.7 \\
& Deltamethrin10EC (Bayer Crop Sciences, Pakistan) & 795 & 12.8 \\
& Cypermethrin 10EC (Bayer Crop Sciences, Pakistan) & 795 & 13.9 \\
Labor & Daily wages application ${ }^{-1} \mathrm{ha}^{-1}$ & & 2.9 \\
Seed cotton & Rate of seed cotton in US\$ Ton & & 475 \\
\hline
\end{tabular}

Labor Cost (daily wages): US\$ 2.9 /application/ha.

Rate of seed cotton for one Ton US\$ 475 (Mean of two years) (Source: Statistics Section CCRI, Multan).

\section{RESULTS}

Three-way ANOVA with the variables, genotypes, (CIM-496 and CIM-506), treatments (five thresholds levels) and the interaction among them was used for fruit damage, larval population and total fruiting parts.

Fruit damage by E. vittella larvae in both the genotypes (CIM-496 and CIM-506) was statistically similar (2009: $\mathrm{F}_{(1,2)}=1.29 ; P>0.05$ and 2010: $0.01 ; P$ $>0.05$ ) having no interaction between genotypes and treatments (five different percent damage levels) for fruit damage (2009: $\mathrm{F}_{(4,106)}=0.06 ; P>0.05$ and 2010: $0.77 ; P$ $>0.05)$. However, it significantly varied among the treatments $\left(2009\right.$ : $\mathrm{F}_{(4,106)}=17.07 ; P<0.050 .00$ and 2010 : $24.84 ; P<0.05)$.

E. vittella larvae showed significantly different response to both genotypes (2009: $F_{(1,2)}=333.06$; $P<0.05$ and 2010: 21.29; $P<0.05)$ and treatments $(2009$ : $\mathrm{F}_{(4,106)}=13.68 ; P<0.05$ and $\left.2010: 17.71 ; P<0.05\right)$ but the interaction between genotypes and treatments for larval population was not significant $\left(2009: \mathrm{F}_{(4,106)}=0.10 ; P>\right.$ 0.05 and 2010: $0.76 ; P>0.05)$.
Number of total fruits significantly differed between the genotypes $\left(\mathrm{F}_{(1,2)} ; P\right.$-values; $2009=21.64 ; 0 P$ $<0.05$ and $2010=127.31 ; P<0.05)$ and the treatments $\left(\mathrm{F}_{(4,106)} ; P\right.$-values; $2009=3.01 ; P<0.05$ and $2010=3.03$; $P<0.05)$. Management using insecticides showed no impact on fruit bearing for both genotypes, but interaction between treatments and genotypes was insignificant $\left(2009 ; \mathrm{F}_{(4,106)}=0.01 ; P>0.05\right.$ and 2010 : $0.06 ; P<0.05)$.

The impact of the insecticides as on the number of damaged fruits, larval population and the yield (tons $\mathrm{ha}^{-1}$ ) are described in Table 3 and 4 for each genotype during the study period of 2009 and 2010.

Application of insecticides for maintaining different infestation level of $E$. vittella significantly kept the population below ETL. Maximum of ten insecticide applications were given to accomplish zero level infestation in the field. Similarly, maximum of seven sprays of insecticides on CIM-496 and eight on CIM-506 were required to keep the fruit damage below 3\% damage threshold level. However, the number of sprays decreased to six and 4-5 applications as the percent damage thresholds increased by 5 and $7 \%$, respectively. The results further revealed that as the \%damage levels 
increased, the number of damaged fruits also increased from 0 to 4.25 , but the larval population remained between 0-1.2 per five plants as damage thresholds increased from $0-7 \%$ (Table 2 ).

Response of both genotypes was significant to insecticide regimes implicating crop yield potential. For CIM-496, yield significantly increased from 0.94to 3.1 tons $\mathrm{ha}^{-1}$ during 2009 and1.44 to 3.72tons ha ${ }^{1}$ during2010, whereas, in CIM-506, yield increased from 0.75 to 2.83 tons ha $^{-1}$ in 2009 and 1.1 to 2.84 tons $\mathrm{ha}^{-1}$ in 2010 comparing the damage levels from 7 to $0 \%$. E. vittella larval damage losses ranged from 62.2 to $68.9 \%$ under unsprayed condition when compared at zero infestation level. In CIM-506, losses ranged from 61.20 to $73.65 \%$ in untreated plots compared to zero damage level (Table 3).

Net monetary profit (NMP) secured in untreated plots for CIM-496 ranged in reverse order of 1101.6120.7 US\$ ha ${ }^{-1}$ during 2009 and 1017.50-128.57 US\$ha ${ }^{-1}$ during 2010 for CIM-496. For CIM-506, reverse NMP ranged from 993.64 -163.48 USD ha ${ }^{-1}$ during 2009 and

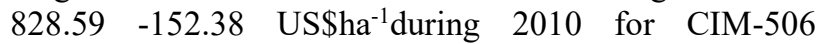
genotype. Number of insecticide applications increased the cost of management which indirectly affected NMP. However, the cost of management decreased from 243.4 and 244.6 US\$ ha-1 at zero\% where as it was 119.4 and 135.1 US\$ha ${ }^{-1}$ at 7\% damage level in CIM-496 (Table 4).

\section{Estimation of economic injury and threshold levels}

Gain-Threshold (GT) based economic injury: Gainthreshold (GT) for zero pest infestation and yield reduction per larva were used for the estimation of yieldbased economic injury level (EIL) and economic thresholds levels (ETL) (Fig 1). EIL was 0.32 (2009) and
0.30(2010) for E. vittella larvae in CIM-496 and 0.30 (2009) and 0.33 (2010) in CIM-506, almost similar for both years. Estimated larval population at ETL was 0.24 and 0.22 per 5 plants or 1.22 and 1.12 larvae per 25 plants in CIM-496. It was 0.23 and 0.25 per 5 plants or 1.13 and1.24larvaeper 25 plants in CIM-506 for observed years (Table 5).

Benefit-Cost Ratio (BCR): Benefit Cost Ratio (BCR) derived from net monitory profit (NMP) and cost of protection $(\mathrm{CP})$ revealed a decrease in BCR from 4.2 and 4.5 to 1.08 and 1.01 in CIM-496 and 4.06 and 3.64 to 1.21 and 0.4 in CIM-506 for 2009 and 2010 crop seasons, respectively, where NMP decreased with slight increase of CP. Following Stone and Pedigo (1972) principles of $\mathrm{BCR}=1$, EIL was derived from the regression of $\mathrm{BCR}$ (dependent variable) and larval population per treatment (independent variable) (Fig 2). In CIM-496, there were 1.21 larvae per 5 plants and in CIM-506 1.04 and 0.78 larvae 5 plants, respectively. In long duration cotton genotype CIM-496, ETL for E. vittella was 0.91 per 5 plant or 4.5 larvae per 25 plants. It did not differ much for short duration genotype, CIM-506, where ETL were 0.87 and 0.67 per 5 plants or 3.9 and 3.3 larvae per 25 plants (Table 6).

Zero percent damage is practically not possible in field crop situation; therefore, other levels of percent damage were estimated at 3,5 and $7 \%$ for E. vittella management, Five\% damage level was found safe for CIM-496 with $0.35-0.48 \mathrm{t} /$ ha yield i.e., $11-13 \%$ lower than $3 \%$ damage level and $21-25 \%$ higher from $7 \%$. For CIM506 , ETL at 3\% damage level having $0.49-0.51$ t/ha yield with $20 \%$ higher yield from $5 \%$ damage suggested this level.

Table 2. No of total damage fruit and larval population of $E$. vittella and spray regime at various level of percent damage for two tested genotypes during 2009 and 2010.

\begin{tabular}{|c|c|c|c|c|c|c|c|}
\hline \multirow{2}{*}{$r$} & \multirow[b]{2}{*}{ Treatment } & \multicolumn{2}{|c|}{ No. total damage fruit } & \multicolumn{2}{|c|}{ Larval population } & \multicolumn{2}{|c|}{ No. sprays } \\
\hline & & 2009 & 2010 & 2009 & 2010 & 2009 & 2010 \\
\hline \multirow{5}{*}{ CIM-496 } & $0 \%$ & $0.00 \mathrm{e}$ & $0.00 \mathrm{c}$ & $0.00 \mathrm{~d}$ & $0.00 \mathrm{c}$ & 10 & 10 \\
\hline & $3 \%$ & $1.44 \mathrm{~d}$ & $1.60 \mathrm{~b}$ & $0.60 \mathrm{c}$ & $0.50 \mathrm{~b}$ & 7 & 7 \\
\hline & $5 \%$ & $1.92 \mathrm{c}$ & $2.04 b$ & $0.81 \mathrm{c}$ & $0.64 b$ & 6 & 6 \\
\hline & $7 \%$ & $2.60 \mathrm{~b}$ & $2.18 b$ & $1.08 \mathrm{~b}$ & $0.68 b$ & 4 & 5 \\
\hline & Unsprayed & $4.25 \mathrm{a}$ & $4.37 \mathrm{a}$ & $1.41 \mathrm{a}$ & $1.38 \mathrm{a}$ & 0 & 0 \\
\hline \multirow{5}{*}{ CIM-506 } & $0-1 \%$ & $0.00 \mathrm{~d}$ & $0.00 \mathrm{e}$ & $0.00 \mathrm{~d}$ & $0.00 \mathrm{e}$ & 10 & 9 \\
\hline & $3 \%$ & $1.50 \mathrm{c}$ & $0.82 \mathrm{~d}$ & $0.54 \mathrm{c}$ & $0.39 \mathrm{~d}$ & 8 & 7 \\
\hline & $5 \%$ & $1.77 \mathrm{c}$ & $1.90 \mathrm{c}$ & $0.57 \mathrm{c}$ & $0.73 c$ & 7 & 6 \\
\hline & $7 \%$ & $2.73 b$ & $2.63 b$ & $0.94 b$ & $1.03 \mathrm{~b}$ & 4 & 4 \\
\hline & Unsprayed & $4.64 \mathrm{a}$ & $5.24 \mathrm{a}$ & $1.26 \mathrm{a}$ & $1.81 \mathrm{a}$ & 0 & 0 \\
\hline
\end{tabular}

Using DMR test means followed by the same letter in a column are not significantly different at $\mathrm{p}=0.05$. 
Table 3. Yield of seed cotton and percent loss in yield of CIM-496 and CIM-506 during 2009 and 2010.

\begin{tabular}{|c|c|c|c|c|c|}
\hline \multirow{2}{*}{ Genotypes } & \multirow{2}{*}{ Treatment } & \multicolumn{2}{|c|}{ Yield (Tone $\mathrm{ha}^{-1}$ ) } & \multicolumn{2}{|c|}{ Yield loss (\%) Over0-1 \% damage level } \\
\hline & & 2009 & 2010 & 2009 & 2010 \\
\hline \multirow{5}{*}{ CIM-496 } & $0-1 \%$ & $3.10 \mathrm{a}$ & $3.72 \mathrm{a}$ & 0.0 & 0.0 \\
\hline & $3 \%$ & $2.34 \mathrm{~b}$ & $2.93 \mathrm{~b}$ & 24.52 & 21.08 \\
\hline & $5 \%$ & $2.0 \mathrm{c}$ & $2.45 \mathrm{~b}$ & 35.81 & 34.17 \\
\hline & $7 \%$ & $1.24 \mathrm{~d}$ & $1.65 \mathrm{c}$ & 60.22 & 55.43 \\
\hline & Unsprayed & $0.96 \mathrm{e}$ & $1.40 \mathrm{c}$ & 68.93 & 62.24 \\
\hline \multirow{5}{*}{ CIM-506 } & $0-1 \%$ & $2.83 \mathrm{a}$ & $2.84 \mathrm{a}$ & 0.0 & 0.0 \\
\hline & $3 \%$ & $2.22 \mathrm{~b}$ & $2.25 \mathrm{~b}$ & 21.65 & 20.75 \\
\hline & $5 \%$ & $1.63 \mathrm{c}$ & $1.69 \mathrm{c}$ & 42.47 & 40.68 \\
\hline & $7 \%$ & $1.09 \mathrm{~d}$ & $1.21 \mathrm{~d}$ & 61.53 & 57.33 \\
\hline & Unsprayed & $0.75 \mathrm{~d}$ & $1.10 \mathrm{~d}$ & 73.65 & 61.20 \\
\hline
\end{tabular}

Using DMR test means followed by the same letter in a column are not significantly different at $\mathrm{p}=0.05$.

Table 4. Net monitory profit (NMP) on yield over untreated plots, cost of protection (CP) in (US \$ ha ${ }^{-1}$ ) and gain threshold (GT).

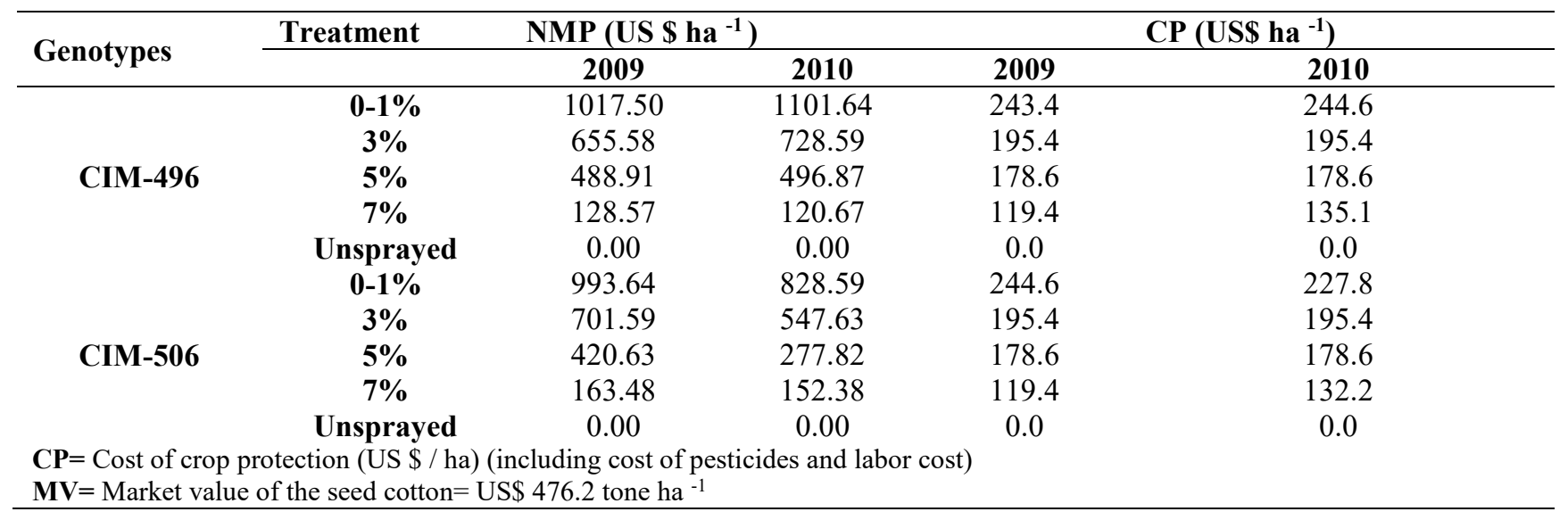

Table 5. Economic injury (EIL) and threshold levels (ETL) estimated with gain threshold (GT) level) for E. vittella in two cotton genotypes.

\begin{tabular}{|c|c|c|c|c|c|}
\hline \multirow[t]{2}{*}{ Genotypes } & \multirow[t]{2}{*}{ Treatment } & \multicolumn{2}{|c|}{$G T=C P / M V$} & \multicolumn{2}{|c|}{$E I L=G T / b$} \\
\hline & & 2009 & 2010 & 2009 & 2010 \\
\hline \multirow[t]{5}{*}{ CIM-496 } & $0-1 \%$ & 0.51 & 0.51 & & \\
\hline & $3 \%$ & 0.41 & 0.41 & $\mathrm{EIL}=0.32 \mathrm{lar} / 5$ plants; & $=0.30 \mathrm{lar} / 5$ plants \\
\hline & $5 \%$ & 0.38 & 0.38 & $\mathrm{ETL}=0.24 \mathrm{lar} / 5$ plants; & $=0.22 \mathrm{lar} / 5$ plants \\
\hline & $7 \%$ & 0.25 & 0.28 & $\mathrm{ETL}=1.22 \mathrm{lar} / 25$ plants; & $=1.12 \mathrm{lar} / 25$ plants \\
\hline & Unsprayed & 0.0 & 0.0 & & \\
\hline \multirow[t]{5}{*}{ CIM-506 } & $0-1 \%$ & 0.51 & 0.48 & & \\
\hline & $3 \%$ & 0.41 & 0.41 & $\mathrm{EIL}=0.30 \mathrm{lar} / 5$ plants; & $=0.331 \mathrm{ar} / 5$ plants \\
\hline & $5 \%$ & 0.38 & 0.38 & $* \mathrm{ETL}=0.23$ lar $/ 5$ plants; & $=0.25 \mathrm{lar} / 5$ plants \\
\hline & $7 \%$ & 0.25 & 0.28 & $\mathrm{ETL}=1.13 \mathrm{lar} / 25$ plants; & $=1.24 \mathrm{lar} / 25$ plants \\
\hline & Unsprayed & 0.0 & 0.0 & & \\
\hline
\end{tabular}


Table 6. Economic injury (EIL) and threshold levels (ETL) estimated with benefit and cost ratio (BCR) for $E$. vittella in two cotton genotypes

\begin{tabular}{|c|c|c|c|c|c|c|}
\hline \multirow{2}{*}{ Genotypes } & \multirow[t]{2}{*}{ Treatment } & \multicolumn{2}{|c|}{$B C R=N M P / C P$} & \multicolumn{3}{|c|}{ Regression equation, EIL and ETL } \\
\hline & & 2009 & 2010 & & 2009 & 2010 \\
\hline \multirow{5}{*}{ CIM-496 } & $0-1 \%$ & 4.2 & 4.5 & & & \\
\hline & $3 \%$ & 3.36 & 3.73 & $\mathrm{EIL}=$ & $1.21 \mathrm{lar} / 5$ plants & $=1.21 \mathrm{lar} / 5$ plants \\
\hline & $5 \%$ & 2.74 & 2.78 & $* \mathrm{ETL}=$ & 0.91 lar/ 5 plants & $=0.91 \mathrm{lar} / 5$ plants \\
\hline & $7 \%$ & 1.08 & 1.01 & $\mathrm{ETL}=$ & 4.5 lar/ 25 plants & $=4.5$ lar $/ 25$ plants \\
\hline & Unsprayed & 0.00 & 0.00 & & & \\
\hline \multirow{5}{*}{ CIM-506 } & $0-1 \%$ & 4.06 & 3.64 & & & \\
\hline & $3 \%$ & 3.59 & 2.80 & $E I L=$ & 1.04 lar/ 5 plants; & $=0.78 \mathrm{lar} / 5$ plants \\
\hline & $5 \%$ & 2.36 & 1.56 & $* \mathrm{ETL}=$ & 0.89 lar/ 5 plants; & $=0.67$ lar $/ 5$ plants \\
\hline & $7 \%$ & 1.21 & 0.40 & $\mathrm{ETL}=$ & 3.9 lar/ 25 plants; & $=3.3 \mathrm{lar} / 25 \mathrm{plants}$ \\
\hline & Unsprayed & 0.00 & 0.00 & & & \\
\hline
\end{tabular}

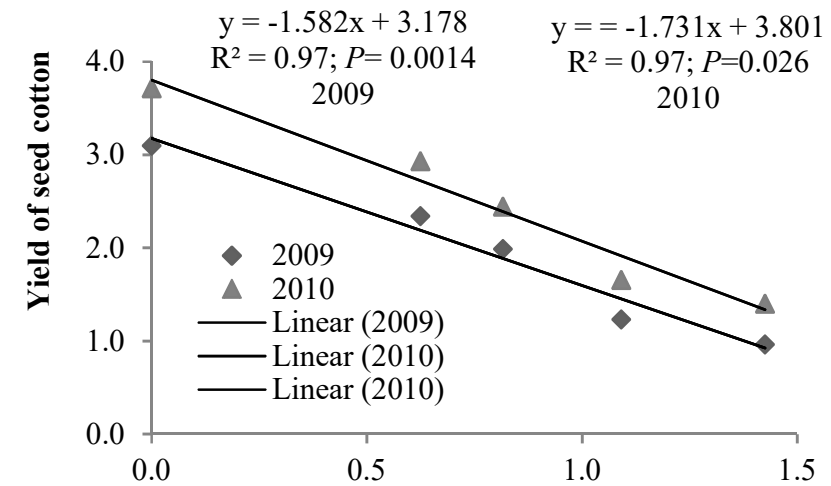

a

$$
\text { Lar. Pop. }
$$

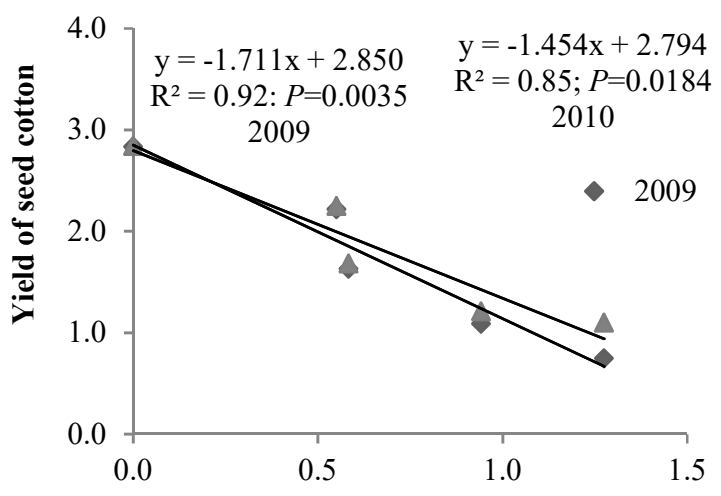

b

Lar. Pop.

Fig 1 Regression of yield (tons/ ha) and larvae per 5 plants to determine yield loss per larva $($ Coefficient $=\mathbf{b})$.

\section{a. CIM-496}

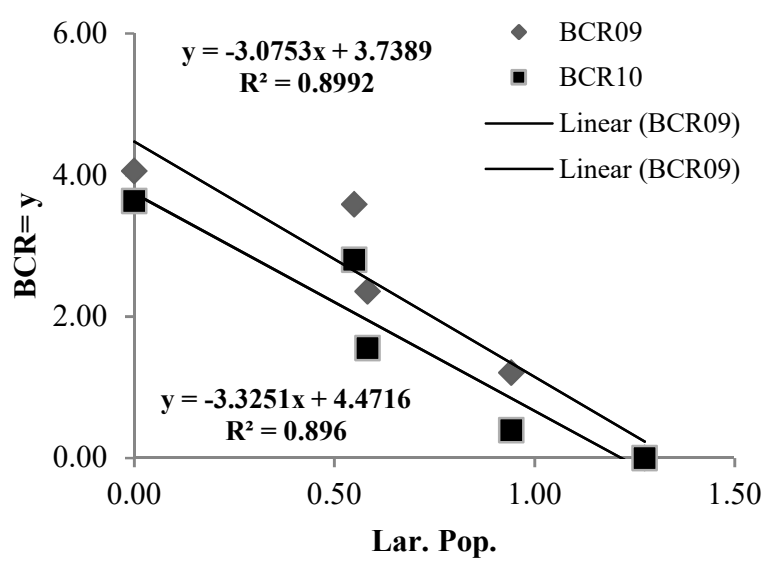

b. CIM-506

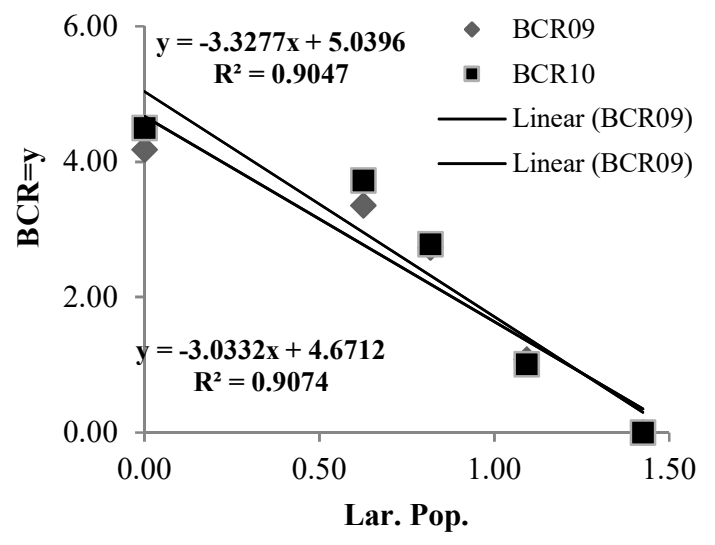

Fig 2 Regression of BCR and larvae per week per 5 plants to determine larval population at EIL
a. CIM-496
$\leftrightarrow$
b. CIM-506 


\section{DISCUSSION}

In the present study, a greater number of total fruiting bodies and higher yield (0.27-0.88 ton ha${ }^{1}$ higherin long duration genotype CIM-496 over short duration genotype CIM-506 at 0\% damage levels) and comparatively more damage in CIM-496 was the impact of crop maturity duration. The short season cotton variety offers no compensation time for early season square loss in case of early infestation of $E$. vittella, which needs more protection of these squares than those formed late in the season (Ahmad and Malik 1996). Full-season genotype compensates for pest damage by producing additional bolls to replace those lost due to early- and mid-season infestation of E. vittella (Raper and Gwathmey 2014). However, E. vittella larvae preferred both the genotypes equally as there was no significant difference in the fruit damage between the genotypes. Such preferences might also be due to similarities in nutritional food quality and antibiosis in varieties (Singh and Bichoo 1989, Sayyed et al. 2003).

These genotypes (with different duration) also interfered with ETL of E. vittella responding to the pest infestation. Currently, the control of E. vittella in cotton was primarily through insecticide applications, which reinforced the importance of appropriate pest management as evident from the present results that 60 $74 \%$ yield losses occurred when this pest was not controlled.

Threshold-based spraying decision programmes are an important option in integrated pest management (Silvie et al. 2001). As of today, threshold based chemical spray measures were used for the management of $E$. vittella on short and long duration genotypes in the present study. Threshold based insecticide applications with rotational sprays of cypermethrin, deltamethrin and spinosad instead of calendar-based chemical sprays were good exercises against $E$. vittella having significant results. The present results reveal that with the incremental increase in percent damage threshold levels (from 0 to 3 to 5 to $7 \%$ ), the number of insecticides applications decreased. It means that at the lower threshold level the interval between two spray applications was shorter to achieve the same lower threshold levels whereas at higher threshold level interval between the sprays was longer. Similarly, number of damaged fruits was lower at lower threshold level as compared to higher number of damaged fruits at the higher threshold level. Longer spraying intervals diminished residual activities of insecticides and ultimately E. vittella larval population built up that increased crop losses (Dutcher 2007). Ultimately gradual decrease in seed cotton yields (tone $\mathrm{ha}^{-1}$ ) with decreasing NMP (US\$ ha ${ }^{-1}$ ) compared to $0 \%$ damage levels revealed the impact of the spray program on E. vittella management. Previously Sahoo and Pal (2003), and Iqbal et al. (2014) have reported that yield of seed cotton enhances with the use of conventional insecticides for $E$. vittella management.

The foremost goals of IPM include reducing $E$. vittella population to its lowest status, accepting the presence of a tolerable E. vittella population and improving farmer profits in seed cotton yield. It is evident from current management strategies which revealed significant impact on the E. vittella larvae with $23-100 \%$ in 2009 and $49-100 \% 2010$ control.

Present study proposes EILs and theoretically fixed ETs, which in relation to percent damage levels can be used as a decision tool leading to an improved control E. vittella. EILs and ETLs are the basic tools for a successful IPM in practice (Higley and Pedigo 1993). The calculation of EILs for different damage level( $0,3,5$ and $7 \%$ ) was made in order to emphasize that the EIL concept is dynamic and depends mostly upon the type and strategy of the insecticide applications chosen by the farmer and its price.

EIL estimated on market value bases (Gain Threshold) is known to vary with changes in crop market value, cost of protection and extent of insect damage. While damage per unit larva (b) is assumed to be relatively constant, both the value of the crop and the cost of control can vary (Obopile, 2006). Therefore, a true economic threshold accommodates fluctuations in pesticides prices and crop value. Thresholds can therefore vary for different pesticides and its application strategies. As a rule of thumb, the lower cost of control and higher crop value result in the lower threshold and vice versa (Miles, 2016).

One commonly used rule of thumb in IPM programs is the adoption of a Benefit: Cost Ratio (BCR) of $2: 1$. This means that action is only taken when the value of likely damage prevented is twice the cost of control. This rule is most feasible where the threshold is based on a very low cost of control (Miles, 2016). The current study showed that the benefit-per-unit cost of insecticides varied with exposure period, which influenced the yield and determined the number of sprays. Reduction in the benefit-to-cost ratio occurred with the increase of percent damage levels as E. vittella larvae increased to higher densities by reduction in number of sprays. This was demonstrated by the significant reduction in yield.

On the bases of GT, BCR and reduction in the yield, ETL suggested at $5 \%$ damage level was found significantly safe for long duration genotype CIM-496. The larval population determined on the base of GT was 1.12-1.22 larvae per 25 plants and on bases of BCR were 4.5 larvae per 25 plants as ETLs. For short duration genotype CIM-506 ETL was found at 3\% damage level. Larval population estimated on GT bases was 1.4-1.33 larvae per 25 plants and on BCR bases were 3.3 to 3.9 larvae per 25 plants. 
This study also showed the importance of timing for the first insecticide application to control E. vittella. Estimated threshold levels could be used to set the first insecticide application to manage the E. vittella for the rest of season, especially for both short and long duration cotton varieties. However, delays in the first application in short duration genotype, CIM-506, especially in August, resulted in significant yield loss. Full season varieties like CIM-496 can absorb the pest shocks in terms of fruit losses in August to some extent. Therefore, intelligent use of insecticides at first appearance of the infestation and for the rest the season at ETL can reduce the number of applications from 8-7 sprays at 3\% damage levels on CIM-506 and 6-7 sprays on CIM-496 at 5\% damage levels. It will reduce the cost of protection (CP) with higher net monitory profit (NMP).

It was also observed that loss of immature fruits contributed significantly to overall yield loss. Therefore, $E$. vittella can be managed if the first spray is applied in early August to protect the immature fruits targeted by the pest to initiate infestation. The crucial period for May sown crops is from August to October for fruit bearing, boll formation, maturation and opening and flaring up of E. vittella and other bollworms (Baloch et al. 1984, Baloch et al. 1990). Present study agrees with the findings that bollworm; especially $E$. vittella infestation affects the development of the cotton crop leading greater yield loss due to higher levels of fruit loss regardless of the genotypes (Chakravarthy and Sidhu 1986, Ahmed et al. 2003, Ahmed et al. 2012).

Conclusion: Insect pest management based on proper pest scouting and application of insecticides at threshold level of pest infestation can help to decrease the number of applications of insecticides, pest infestation and fruit losses. CIM-496 produced a higher yield than CIM-506 due to differences in maturation duration. ETL estimated to apply insecticides to control E. vittella was at 5-6\% damage for CIM-496 and 3-5\% damage for CIM-506 due to less potential of damage tolerance in the short duration genotype. The foremost goals of IPM include reducing $E$. vittella population to its lowest status, accepting the presence of tolerable E. vittella population and improving farmer's profit in seed cotton yield. EILs and theoretically fixed ETL suggested in relation to percent damage levels can be used as a decision tool leading to an improved control of this important insect pest of cotton crop.

Novelty Statement: Insecticides application at selected percent damage levels (5\% for long duration and 3\% for short duration varieties of cotton) kept the E. vittella larval infestation and bolls damage well below from the total fruit losses of $60-74 \%$ in unsprayed treatment on GT and BCR bases.

\section{REFERENCES}

Abhilash, C., and R. H. Patil. 2010. Determination of economic injury level for the soybean pod borer, Cydia ptychora (Meyrick). Karnataka J. Agric. Sci. 21: 446-447

Afzal, M., and M. I. Khan. 2015. Breeders of CIM-496 and CIM-506. Breeding section, Central Cotton Research Institute, Multan. www.ccri.org.pk.

Ahmad, Z., and M. N. Malik. 1996. Short season cotton: how far can it go? Proceedings Belt. Cot. Conf: $32 \mathrm{pp}$.

Ahmed, S., S. Nisar, Z.-u. Rehman, and M. Bashir. 2003. Comparative incidence of insect pest complex on cotton varieties subjected to organic and synthetic fertilizers. Int. J.Agri.\& Bio. 5: 236238.

Ahmed, S., M. K. Iqbal, M. Shahid, and R. R. Khan. 2012. Comparison of antibiosis of spotted bollworm, Earias vittella (Fab.) on two $\mathrm{Bt}$ and one non-Bt cotton varieties. Pakistan J.Zool.44: 463-468.

Anderson, J. M., R. R. Bridge, A. M. Heagler, and G. R. Tupper. 1976. The economic impact of recently developed early-season cotton strains on firm and regional cropping systems and income [Mississippi]. Proceedings Belt. Cot. Conf: 332 pp.

Anonymous. 2015. Economic Thresholds of insect pests, https://www.saskatchewan.ca/business/ economic-thresholds-of-insect-pests.

Arshad, M., A. Wajid, M. Maqsood, K. Hussain, M. Aslam, and M. Ibrahim. 2007. Response of growth, yield and quality of different cotton cultivars to sowing dates. Pakistan J. Agri. Sci., 44: 208-212.

Baloch, A. A., B. A. Soomro, and A. M. Kalroo. 1984. Studies on plant profile and spotted bollworm (Earias insulana and E. vitella) associated with cotton crop. Pakistan Cotttons (Pakistan) 28: 273-281.

Baloch, A. A., B. A. Soomro, M. A. Leghari, and M. W. Sanjrani. 1990. Studies on economic injury levels of insect pests of cotton. Turkish J. Entomology 14.131-140.

Chakravarthy, A. K., and A. S. Sidhu. 1986. Resistance to insect pest damage in four cotton varieties in Ludhiana. International J. Tropical Insect Science 7: 647-652.

Damos, P., and M. Savopoulou-Soultani. 2010. Population dynamics of Anarsia lineatella in relation to crop damage and the development of economic injury levels. J. Appl. Entomol. 134: 105-115.

Dhawan, A., G. Simwat, and A. Sidhu. 1990. Shedding of fruiting bodies by bollworms in Asiatic cottons. 
J. Res., Punjab Agricultural University 27: 441443.

Dutcher J. D. 2007. A review of resurgence and replacement causing pest outbreaks in IPM In: Ciancio A., Mukerji K.G. (eds) General concepts in integrated pest and disease management. Integrated Management of Plants Pests and Diseases, .1. Springer, Dordrecht. pp $27-43$

Higley, L. G., and L. P. Pedigo. 1993. Economic injury level concepts and their use in sustaining environmental quality. Agric., Ecosyst. Environ. 46: 233-243.

Iqbal, J., N. I. Jajja, M. Jamil, and M. W. Hassan. 2014. Field evaluation for efficacy of conventional insecticides and insect growth regualtors against spotted bollworms Earias spp of cotton Pakistan Entomol., 36(2): 97-104.

Khan, R. R., S. Ahmed, M. W. Saleem, and M. Nadeem. 2007. Field evaluation of different insecticides against spotted bollworms Earias spp. at district Sahiwal. Pakistan. Entomologist 29: 129-133.

Kovanci, O. B., B. Kovanci, and N. S. Gencer. 2005. Sampling and development of economic injury levels for Anthonomus rubi Herbst adults. Crop Protection 24: 1035-1041.

McGraw-Hill, C. (2008). Statistix 8.1. Analytical Software, Tallahassee. Maurice/Thomas text, Florida, USA.

Maurice, N. 2010. Serious Pest of Cotton, Spotted Bollworm http://EzineArticles.com/.

Miles, M. 2016. Thresholds IPM Guidelines for Grains IPM Guidelines for Grains.html. $\mathrm{http} /$ ipmguidelinesforgrains.com.au

Nibouche, S., E. Gozé, R. Babin, J. Beyo, and T. Brévault. 2007. Modeling Helicoverpa armigera (Hübner)(Lepidoptera: Noctuidae) damages on cotton. Environ. Entomol. 36: 151-156.

Obopile, M. 2006. Economic threshold and injury levels for control of cowpea aphid, Aphis crassivora Linnaeus (Homoptera: Aphididae), on cowpea. Afr. Plant Prot. 12: 111-115.

Ogunlana, M. O., and L. P. Pedigo. 1974. Economicinjury levels of the potato leafhopper on soybeans in Iowa. J. Econ. Entomol. 67: 29-32.

Raper, T. B., and C. O. Gwathmey. 2014. Guide to Earliness Management in Short-season Cotton Production. University of Tennessee Institute of Agriculture, U.S. Department of Agriculture: 18.
Reddy, C. N., Y. Singh, and V. S. Singh. 2001. Economic injury level of gram pod borer (Helicoverpa armigera) on pigeonpea. Indian J. Entomology 63: 381-387.

Riley, D. G. 2008. Economic injury level (EIL) and economic threshold (ET) concepts in pest management, pp. 1282-1286, Encyclopedia of Entomology. Springer.

Sahoo, S. K., and P. K. Pal. 2003. Effect of alternate use of pesticides on shoot and fruit borers of okra. Environ. Ecol. 21: 960-963.

Sayyed, A. H., H. Cerda, and D. J. Wright. 2003. Could Bt transgenic crops have nutritionally favourable effects on resistant insects? Ecology Letters 6: 167-169.

Silvertooth, J. C., and C. R. Farr. 2001. Management considerations for short season cotton in Arizona. College of Agriculture and Life Sciences, University of Arizona . 6 pp. http://ag.arizona.edu/.

Silvie, P., J.-P. Deguine, S. Nibouche, B. Michel, and M. Vaissayre. 2001. Potential of threshold-based interventions for cotton pest control by small farmers in West Africa. Crop Protect. 20: $297-$ 301.

Singh, Y., and S. L. Bichoo. 1989. Some biological and bionomical observations on Earias fabia Stoll. Bulletin of Entomology (New Delhi) 30: 84-91.

Somashekara, R., S. S. Udikeri, S. B. Patil, and K. Basavanagoud. 2011. Food consumption indices for spotted bollworm,Earias vittella (Fab.), on transgenic cottons expressing one or two $\mathrm{Bt}$ genes. Karnataka J. Agri. Sci. 24.

Stone, J. D., and L. P. Pedigo. 1972. Development and economic-injury level of the green cloverworm on soybean in Iowa. J. Econ. Entomol. 65: 197201.

Vennila, S., V. K. Biradar, P. R. Panchbhai, J. G. Gadpayle, A. Y. Deshmukh, P. W. Nemade, and P. P. Karanjkar. 2005. Seasonal dynamics, survival and feeding preference of Earias vittella (Fab.) larval instars on cotton. Annals of Plant Protection Sciences 13: 60-64.

Zahid, M. A., M. M. Islam, M. H. Reza, M. H. Z. Prodhan, and M. R. Begum. 2008. Determination of economic injury levels of Helicoverpa armigera (Hubner) in chickpea. Bangladesh J Agricultural Research 33: 555563. 